\title{
An Assessment of Bioclimatic Conditions for Tourists- A Case Study of Mashhad, Iran
}

\author{
Reza Esmaili $^{1^{*}}$, Gholamabbas Fallah Ghalhari ${ }^{2}$ \\ ${ }^{1}$ Department of Architecture, Mashhad Branch, Islamic Azad University, Mashhad, Iran \\ ${ }^{2}$ Department of Geography and Environmental Sciences, Hakim Sabzevari University, Sabzevar, Iran \\ Email: "․․Esmaili.n@gmail.com, ab_fa789@yahoo.com
}

Received October 23, 2013; revised November 22, 2013; accepted November 30, 2013

Copyright (c) 2014 Reza Esmaili, Gholamabbas Fallah Ghalhari. This is an open access article distributed under the Creative Commons Attribution License, which permits unrestricted use, distribution, and reproduction in any medium, provided the original work is properly cited. In accordance of the Creative Commons Attribution License all Copyrights (c) 2014 are reserved for SCIRP and the owner of the intellectual property Reza Esmaili, Gholamabbas Fallah Ghalhari. All Copyright (c) 2014 are guarded by law and by SCIRP as a guardian.

\section{ABSTRACT}

Weather and climate have a double-edged effect on tourism. It can be considered both as a limiting and a developing factor for tourism. In this regard, having access to precise bio-climatic information can be of high use to enhance the quality of tourism services. This study has evaluated the Bio-climatic conditions of the tourists in Mashhad, a North-Eastern city in Iran, through the use of thermo-physiological indicator of physiological equivalent temperature (PET). Studies have been done for the hours of 9:30, 12:30 and 21:30 of the local time using the statistical data of the period between 1978 and 2007. According to the results, the longest period of climatic-comfort-hours is around 21:30 (mainly in June, July, and August), and the shortest duration of climatic-comfort-hours is around 9:30 (sporadically assessed in April, May and October). The Bio-climatic conditions during the Nowruz Holidays are only comfortable in the evenings. Especially, there is the challenge of cold stress in the mornings and more specifically, at nights. However, the best condition of the whole assessed times in summer holidays (that is June 22nd to September 23rd) is at 21:30. Summer days are not ideal for tourism due to the heat stress. The daily change of PET index shows a Gaussian curve, the peak of which (indicative of too much heat stress) shows July, and non-stress condition can be seen on both sides of this curve.

\section{KEYWORDS}

Bio-Climate; Climate-Comfort; Nowruz Holidays; Mashhad

\section{Introduction}

Over the past six decades, tourism has experienced continued expansion and diversification. It has become one of the largest and fastest growing economic sectors in the world. In spite of many shocks, long-term trends are indeed impressive: tourism rose from 25 million International Tourist Arrivals (ITA) in 1950 to a record 980 million ITA in 2011 [1].

The overall export income generated by inbound tourism, including passenger transport, exceeded US\$ 1.2 trillion in 2011, or US\$ 3.4 billion a day on average. Tourism exports account to as much as $30 \%$ of the world's exports of commercial services and 6\% of overall exports of goods and services. Globally, as an export

\footnotetext{
"Corresponding author.
}

category, tourism ranks the fourth after fuels, chemicals and food.

According to Tourism Towards 2030, the number of international tourist arrivals worldwide is expected to increase by an average of 3.3\% a year over the period 2010 to 2030. Over time, the rate of growth will gradually slow down, from $3.8 \%$ in 2011 to $2.5 \%$ in 2030, but on top of growing base numbers. In absolute numbers, international tourist arrivals will increase by some 43 million a year, compared to an average increase of 28 million a year during the period 1995 to 2010. At the projected pace of growth, international tourist arrivals worldwide will exceed 1 billion in 2012 and reach 1.8 billion by the year 2030 [1].

Tourism is strongly affected by climate conditions and suitable climatic conditions are considered as sources of 
investment [2]. Weather and climate have a broad significance to tourist decision-making and the travel experience, significantly influencing travel patterns and expenditures worldwide. Climate is a key factor considered by tourists, consciously or implicitly during travel planning, and represents both a push and pull factor for tourists [3]. Nowadays, many tourists decide their region and time of journey based on weather conditions. An international survey of 66 national tourism and meteorological organizations found that a large majority (81\%) felt that weather and climate were major determinants of tourism in their nation [4]. Hence, due to the considerable increase of tourists in recent decades and the role of ideal weather as a central factor in choosing tourism destinations, the importance of having access to bioclimatic information is highly conceivable [5].

Generally, the study of climate effects on the human body is done through bio-climatic science. This science presents the complicated and simultaneous effects of climatic variables on human body in simple forms as bioclimatic indices. These indices present numeric values to become understandable for people, and to provide comparisons for different areas through bioclimatic aspects [6]. The latest progresses of bioclimatic science in recent decades have resulted in the emergence of three groups of indices. The first group is empirical indices, such as uncomfortable index [7], wind-chill [8]. The second set is synthetic and bio-climatic indices such as [9-11]. The third set, emerging from thermo-physiological, is known as physiological-thermal parameters; some of the most renowned of which are Physiological Equivalent Temperature PET [12-15], Predict Mean Vote, PMV, Standard Effective Temperature, SET [16], and outdoor standard effective temperature OUT SET [17]. An ideal bioclimatic index should include physical, physiological, and psychological parameters; besides, the energy balance between body and atmosphere should be considered [6] (Figure 1).

Iran, among the world's eighth leading countries considering its cultural and historical sites, and based on the diversity of landscape and continental ecotourism attractions, ranked in the top five countries of the world. However, little research has been done to establish environmental and continental information for tourists. Most of the studies done in Iran have used the primary and synthetic indicators such as Olgy, Gyvny [18], Trojung [19], effective temperature index [20], and TCI [21]. They often used a monthly time scale, and just the biological aspects of climate have been assessed. Besides, applied climate research in this field is very limited ([2224]).

The purpose of the present study is to assess comfortable temperature of Mashhad for tourists on an hourly scale, because the city is one of the most important historical and religious tourism resorts in Iran. The assessment is done via Physiological Equivalent Temperature PET on an hourly scale and the most suitable times for tourism and for traveling to Mashhad are depicted.

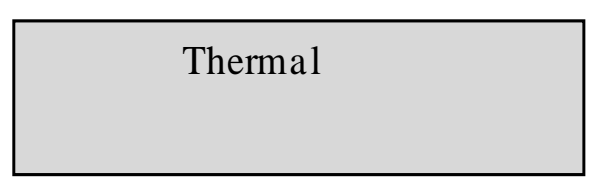

Integrated effects of

- a ir temperature, wind,

- solar radiation,

-Long wave radiation,

-humidity

-Metabolic rate

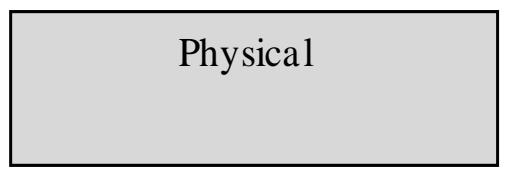

•wind

•rain

-snow/ice

-extreme weather

- air quality uv

-odors/noise

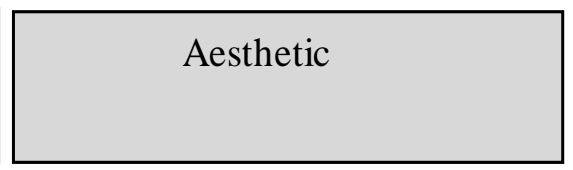

-sunshine

•visibility

-fog

•length of day
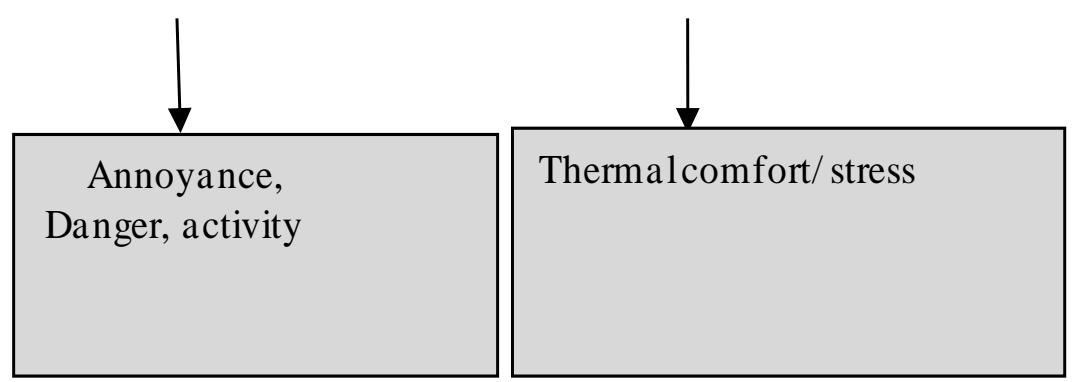

Figure 1. Facets of climate in tourism (de Freitas, 2003). 


\section{Methods and Data}

\subsection{Area under Study}

Mashhad is the second most populated city in Iran, with $8 \%$ of the total population of the country, located in the province of Khorasan Razavi. It is located between $37^{\circ}$ to $32^{\circ}$ north latitude and $40^{\circ}$ eastern longitudes, 999 meters above the sea level (Figure 2). Based on the Coupon classification, the city has a cold semi-arid climate (BSK) [25]. Respectively, $19.1 \%$ of Iran is dominated by this type of climate. Thanks to the mausoleum of the Shiite's Eighth Late Leader (Imam Reza), Mashhad is Iran's most important Religious tourism center. Besides, Firdausi's mausoleum (the greatest Persian epic poet who lived in 10th century) attracts millions of tourists to itself annually. According to the records of Cultural Heritage and Tourism Organization of Khorasan Razavi, annually 25 to 30 million pilgrims and tourists visit Mashhad. Distribution of tourists throughout the years is shown in Figure 3.

\subsection{Data}

To assess Physiological Equivalent Temperature, this study used the Meteorological data from Mashhad synoptic station. The necessary data included mean temperature, relative humidity, wind speed, pressure, water vapor, and cloudy days; all of which were obtained daily, for mornings (06 UTC time or 9:30 local time), afternoons (12 UTC time or 15:15 local time), and nights (18
UTC or 21:30 local time). Furthermore, the daily mean (average of daily data) in a 20-year period (1978-2007) is included. The meteorological data has been obtained from Meteorological Organization of Iran. In addition, the frequency of occurrence of climatic phenomena has been calculated and presented on a monthly scale.

\subsection{Physiological Equivalent Temperature (PET)}

To assess the impact of climate on human comfort and climate comfort studies, variety of models and indicators are invented and developed in the second half of the twentieth century, among which, the models based on energy balance equation of the human body are more praised and have attracted more attention [26]. The first model of the heat balance was introduced and described by Fanger [27], which is still in use. This heat index presented the prediction indices of mean vote (PMV) and the percentage of dissatisfaction (PPD), to assist engineers in designing an indoor condition. Two decades later, Jendertzky et al. (1990) were succeeded in assigning suitable variables to Fanger method to modify it for the outdoors conditions [28]. This model is known today as MEMI model [29]. MEMI model stands for the energy balance for human. MEMI model is a part of thermophysiological heat balance models, which are the basis of PMV and PET model. MEMI model is an energy balance equation based on the human body as shown in the following equation [14]:

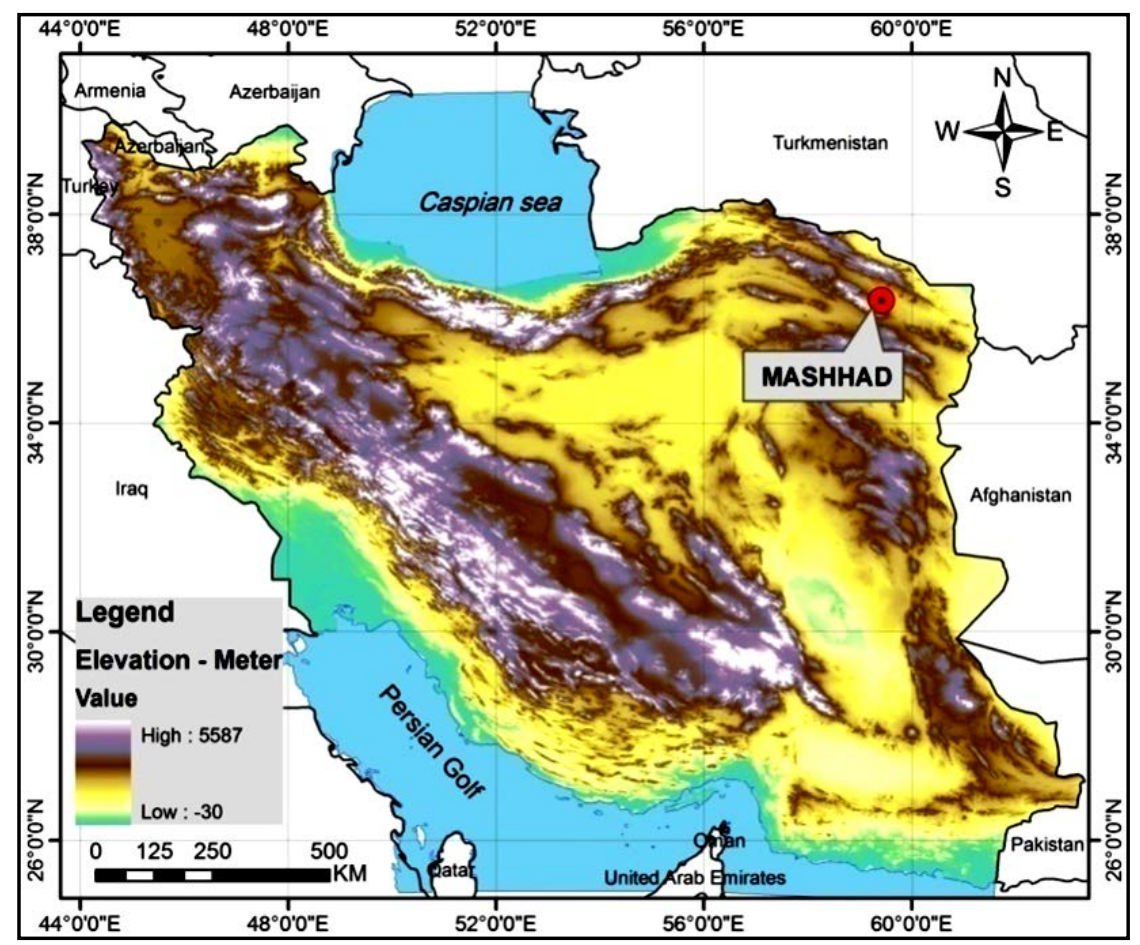

Figure 2. The geographical location of Mashhad, Iran. 


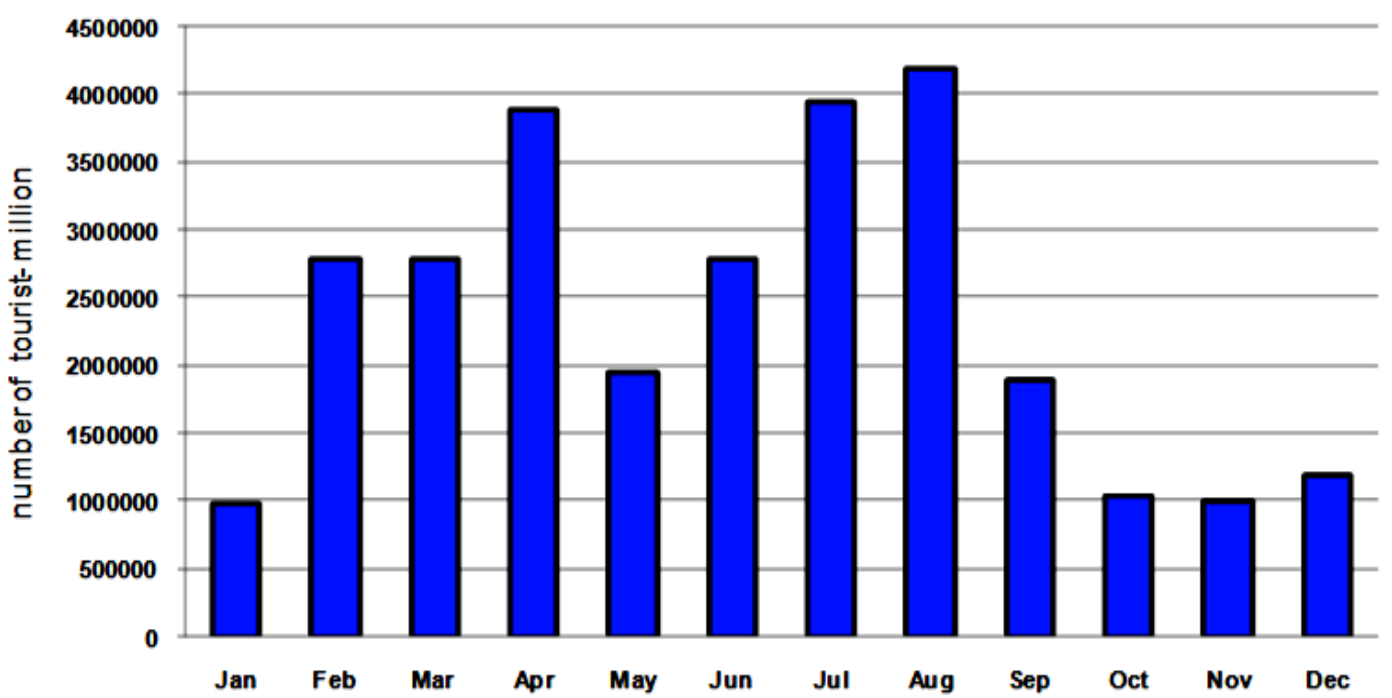

Figure 3. Distribution of the number of tourists to the city of Mashhad in the years.

$$
\mathrm{M}+\mathrm{W}+\mathrm{R}+\mathrm{C}+\mathrm{E} \mathrm{D}+\mathrm{ERe}+\mathrm{E} \mathrm{sW}+\mathrm{S}=0
$$

Where, $\mathrm{M}$ is the rate of metabolism, $\mathrm{W}$ is the output of the physical work, $\mathrm{R}$ is radiation of body, $\mathrm{C}$ is the heat convection, ED is the latent heat of evaporation on the skin, ERE is the sum of thermal effect of heating and evaporation and transpiration, and ESW is the effective air flow in body's evaporation and sweating. All terms in this equation are based on Watt sunlit; $M$ is a positive value; and $\mathrm{W}, \mathrm{ED}$, and ESW are often negative. In this case, if the body is gaining energy, equation is positive, and if it's loosing energy the equation is negative. The above equation is controlled by the following climate variables $([13,14])$ :

- Temperatures: C, ERE

- Humidity: ED, ERE, ESW

- Wind speed: C, ESW

- Mean radiant temperature: $\mathrm{R}$

Among MEMI model outputs the Physiological Equivalent Temperature index (PET) is one of the most comprehensive and widely used indicators to evaluate environmental conditions of climate for tourism [30]. The main advantage of this index is that its output is based on Centigrade. So the results can be understandable for the tourists and the tourism planners who may not be familiar with the environmental climate jargons. Table 1 presents numerical thresholds of this index, as well as the heat sensitivity and physiological conditions related to it. According to Table 1, the range from 23 to 29 degrees centigrade is considered as the climatic comfort. It is noted that a little warmness $(23<$ PET $<29)$ and a little coldness $(13<$ PET $<18)$ can be managed by wearing a jacket to change the uncomfortable climatic conditions into a comfortable one that is suitable for tourism [31]. Therefore, practically the numerical values of PET between 13 to 29 degrees centigrade are considered as a
Table 1. PET threshold values of the different degrees of sensitivity [15].

\begin{tabular}{ccc}
\hline PET $\left({ }^{\circ} \mathbf{C}\right)$ & Thermal sensitivity & Grade of physiologic stress \\
\hline 4 & Very cold & Extreme cold stress \\
8 & Cold & Strong cold stress \\
13 & cool & Moderate cold stress \\
18 & Slightly cool & Slightly cold stress \\
23 & Comfort & No thermal stress \\
29 & Slightly warm & Slightly heat stress \\
35 & warm & Moderate heat stress \\
41 & Hot & Strong heat stress \\
& Very hot & Extreme heat stress \\
\hline
\end{tabular}

comfort zone. To calculate PET, Ray-Man software has been used [32]. This software has the ability to estimate the average temperature of the radiation (Ttmr), thermo physiological PET, PMV, and SET indices.

Required data includes locational data (latitude, longitude, and altitude), climatic data (temperature, relative humidity, vapor, pressure, wind speed, and cloudy day) and personal profile data (height, weight, the default sex); in this regard the sample of the study is of $175 \mathrm{~cm}$ height, $75 \mathrm{~kg}$ weight, and the male genders are considered. The thermo-physiological data (including the amount and type of activity, and the heat resistance of clothing, estimated as 0.9 clo, and the amount of activity is $4 \mathrm{~km}$ per 
hour) [32]. Figure 4 shows the flowchart of continental-thermo human environment.

\section{Results and Discussion}

\subsection{Hourly Assessment}

Tourists are to enjoy the natural and geophysical resources and other attractions in the destination. In this regard, climate is an important geophysical factor that dramatically affects the tourism industry. Many tourists and tourism planners are looking for an easy access to climate information on a short time scale (e.g., hourly); so that they would be able to choose the best times for visiting, shopping or pilgrimage. In this study, the selected hours of the local time representing morning, afternoon and early evening, 09:30 am, 15:30 pm, and 21:30 pm, have been assessed. Rayman model output results for the selected hours, based on the categorization and in a matrix form, including 365 cells representing the whole year span, were calculated for the thermal sensitivity of PET and are presented in Figure 5.

As shown in Figure 5, the days of January, February and December are in the heat-sensitive conditions of cold and too cold days. The cool tension at 21:30 is also observed at the end of February. It is due to Siberia high pressure that causes cold and dry climate during the cold season in the North East of Iran, which makes limits to environmental climate for tourists during this time period.

March 21, coinciding with spring and the Persian New
Year in Iran, the first thirteen days of which are considered as the New Year holidays (Nowruz, the Persian's ancient feast, from March 21th to May 3rd), is considered as the most intensive period of intra-national trips in Iran. It should be noted that most of these internal travels are headed to Mashhad based on its religious, historical and cultural heritage. According to Figure 5, if we consider 9.30 am as the basis time for climatic comfort assessment, the most appropriate time to devote to travel is in late April, early May, and the late September to early November. On the other hand, if we select 15:30 pm, we observe that the comfort climate time in the fall begins later while in spring it begins earlier. Similarly, if the analysis basis time be 21:30, the climate comfort time starts at late June and lasts until mid-August.

As can be seen, Mashhad is protected from heat stress at night throughout the year. Instead, at the same time, the duration of cold stress is higher. Consequently, it can be inferred that the climatic comfort time of the day is divided into three periods. The first period is from midApril until May, the second from end of May to midSeptember, and the third period is from mid-September to mid-November.

The longest period of climatic comfort occurs at 21:30 p.m. for about 61 days, and the minimum period occurs at 9:30 am. with duration of 35 days. The longest period of heat stress occurs at 15:30 which begins in May 25th, lasting to September 24th for about 119 days. The longest period of cold stress also occurs at 21:30, which approximately begins from early October to Mid-April for

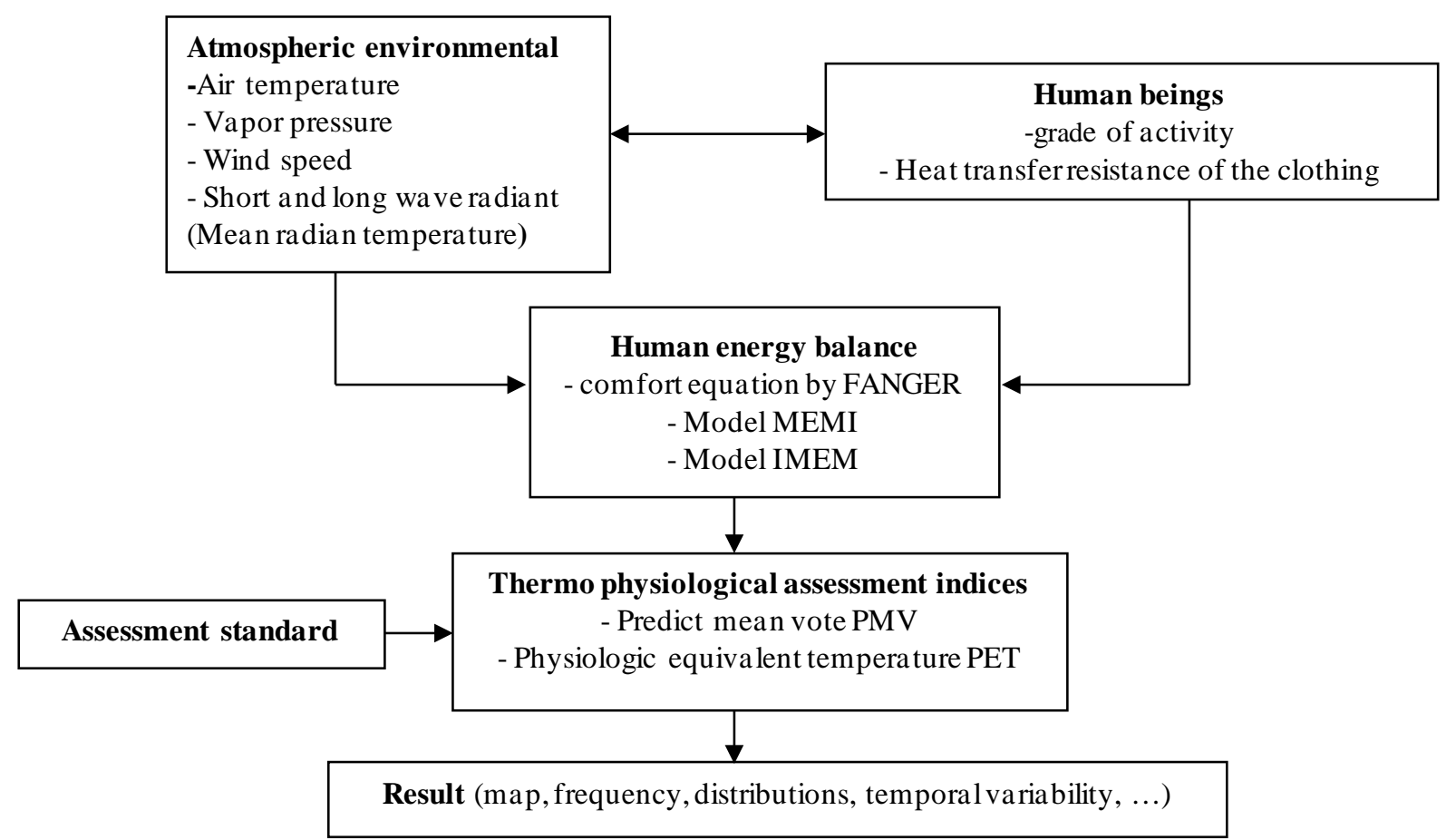

Figure 4. Human environment assessment based on temperature [33]. 

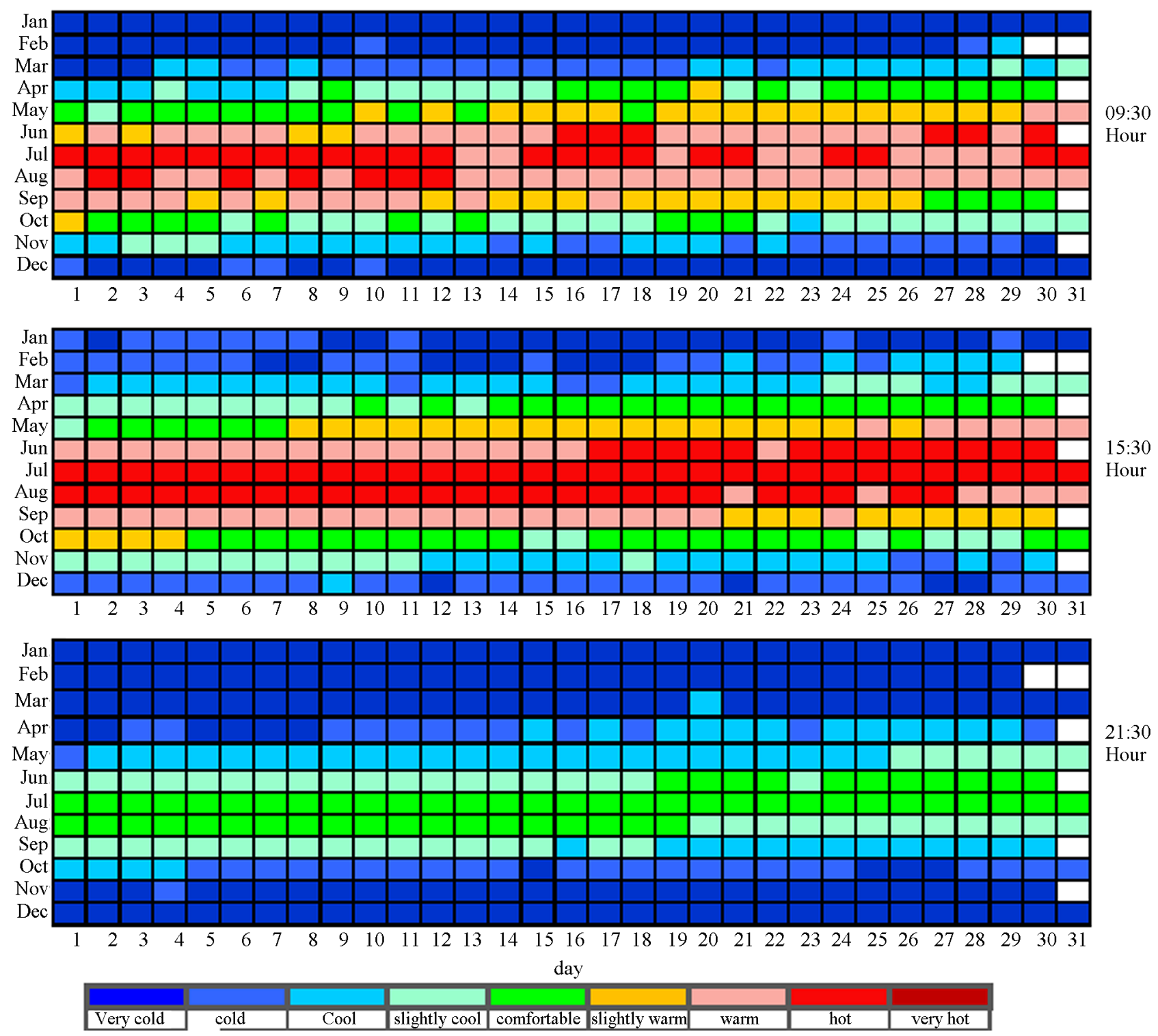

Figure 5. Yearly Bio-climatic conditions in Mashhad.

160 days. The minimum period of cold stress occurs at 15:30, beginning from November 12th to March 28th, for a period of 131 days. June should be considered as the beginning of Heat-stress tensions. During the warm period of the year, all of Iran is covered by Azores subtropical high pressure, with a relatively dry and stable air [34]. Summer season in Iran (June 22nd to September 23th), coincided with the holiday period, is considered a peak period of trips in Iran. Subsequently, according to Figure 5, the best time to leave home in summer is 21:30 p.m. Figure 6 shows the frequency of occurrence of the climatic conditions for several days during the entire period of the study. For example, the weather conditions at 9:30 and 21:30 are colder than other time spans. Besides, the occurrence of climatic comfort is at its highest at 15:30.
Figure 7 presents change process in PET parameters for 09:30, 15:30, and 21:30 time spans and the 24 hours average. The climate comfort zones in these charts are shown in different colors. As shown from the figure, the PET index changes over the year in Gaussian shape, with its peak coinciding with high measurements of the PET index (numbers above $30^{\circ} \mathrm{C}$ ), the heat-sensitive, and hot lines; this peak starts in mid-June and continues until mid-September. The minimum measurement of this index is located at the end of the curve in the early January and the end of December. The Nowruz and summer journey peaks are shown in two separate boxes. As can be seen, in the summer (June 22nd to September 22nd) the curve of 21:30 is often located within the range of climatic comfort. It is worth emphasizing that only at the end of summer holidays the range of climatic comfort 

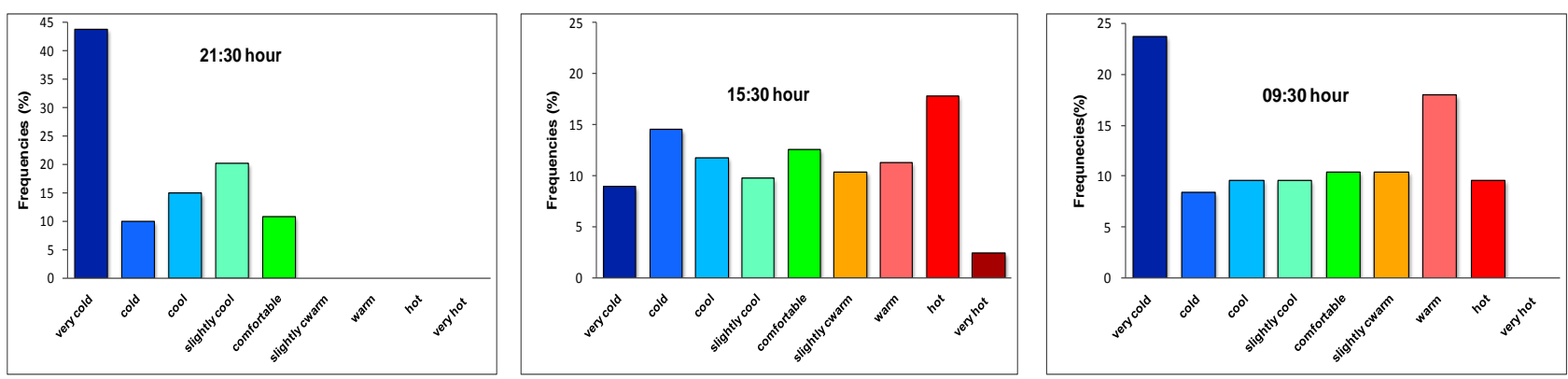

Figure 6. The frequency of occurrence of bio-climatic conditions in daytime.

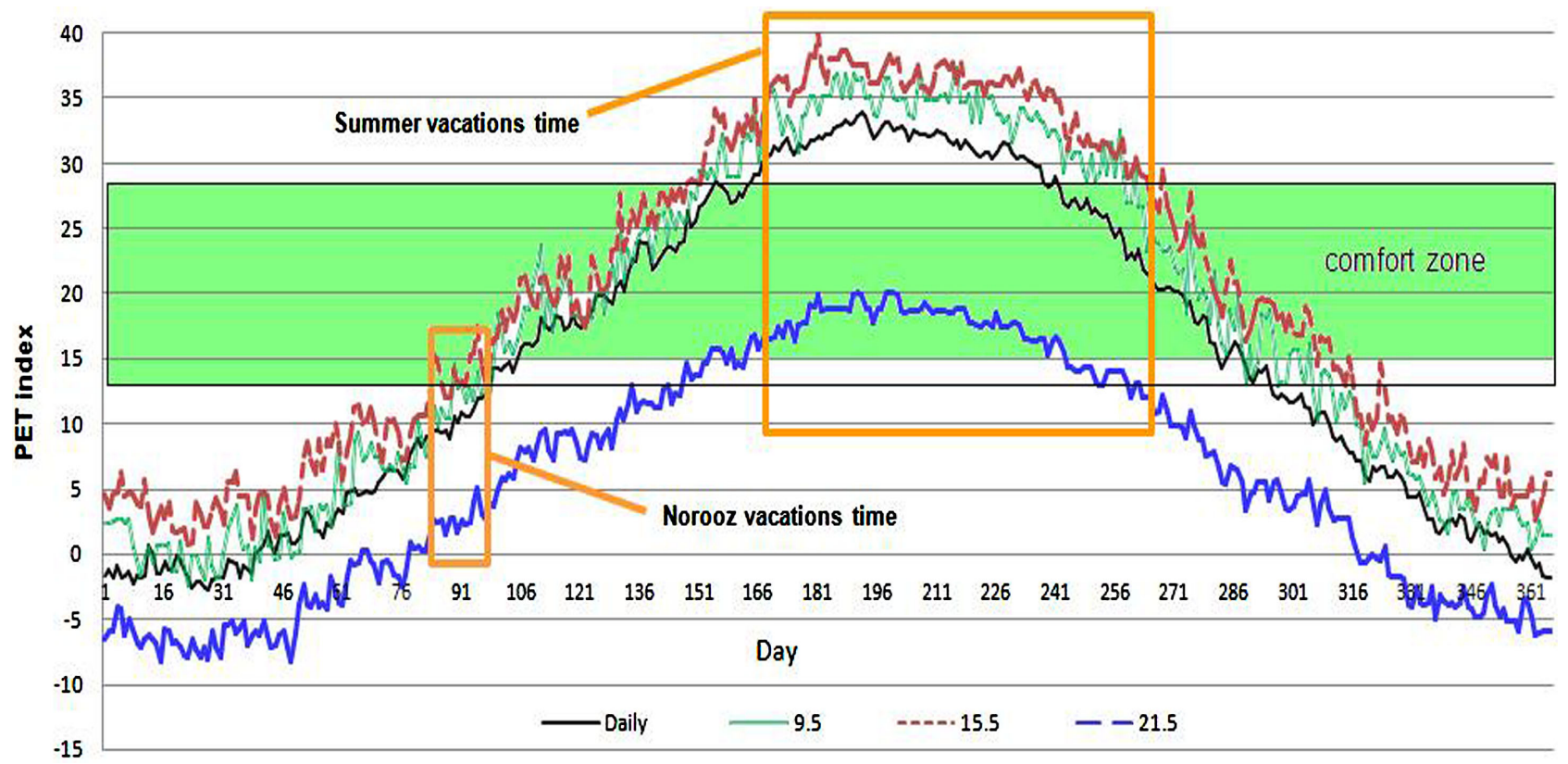

Figure 7. Changes of PET Index for the hours of 09:30, 15:30 and 21:30. the daily average is also shown.

and daily graph curve, identified as 9:30, is in the climatic comfort zone. Also during Nowruz holidays, in early spring (March 21st to May 2nd), only the curves within this range are located in the climatic comfort zone. Throughout the year, the curves for 21:30 are at the bottom and the ones for 15:30 are always higher than others; respectively allocated the lowest and highest index values of PET to them.

\subsection{Recurrences of Phenomena Affecting the Comfort of Tourists}

In spite of the fact that individual environmental information, climate information, and other physical components (such as cloudy day, temperature, humidity, etc.) or the synthesis of environmental parameters such as comfort temperature, and the continental viability indices are of high use for tourists and the tourism planners, these parameters are limited in systematically assessing the effects of atmosphere and its parameters on human. Hence complementary information to the continental viability indices are necessary, such as physical and esthetic parameters; therefore, through using the sum of these information, comprehensive assessment can be made for weather conditions affecting tourists and tourism [6]. Figure 8 shows the frequency of the PET index based on monthly scale in Mashhad. For instance, the highest frequency of being too cold is observed in January, and of being too hot occurs in July. The probability for the occurrence of each of the heat and comfort parameters, such as physiological equivalent, temperature, its amplitudes, and the esthetic parameters, such as cloudy or foggy days, and physical parameters such as wind speed, rainfall, and water vapor pressure, were used for comfortable bio-climatic zone and are shown in Table 2 for each month of the year. The results are done by Excel software and are presented in Figure 9. For example, the probability of a sunny day in January is 40 percent and in March to early July it is 90 percent. Tourists and the tourism sector planners can make a plan based on the probability of each of these phenomena to be able to 


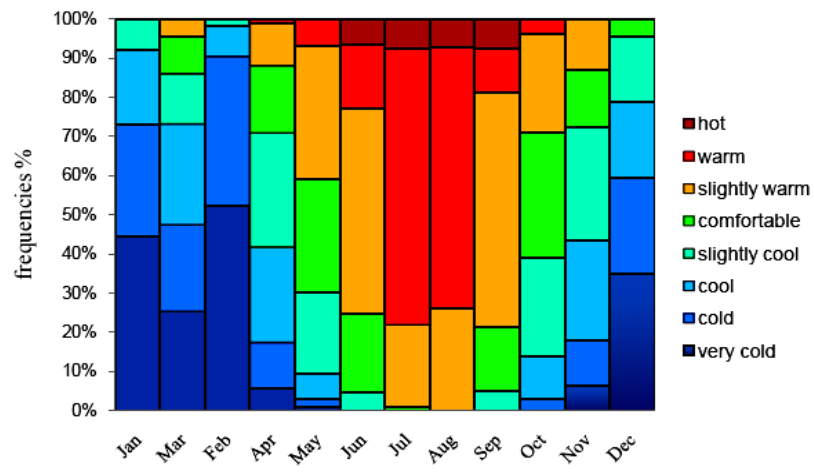

Figure 8. The class diagram of a thermal index PET monthly statistics for the period 1978-2007 Mashhad.
Table 2. Factors, Ranges, and Source of thresholds [35].

\begin{tabular}{ccc}
\hline Factor & Range & Literature \\
\hline Thermal comfort & $18^{\circ} \mathrm{C}<\mathrm{PET}<29^{\circ} \mathrm{C}$ & {$[30]$} \\
Cold stress & $\mathrm{PET}<8^{\circ} \mathrm{C}$ & {$[30]$} \\
Heat stress & $\mathrm{PET}>35^{\circ} \mathrm{C}$ & {$[12]$} \\
Hot day & $\mathrm{PET}>41^{\circ} \mathrm{C}$ & {$[12]$} \\
Stormy day & Wind speed $>8 \mathrm{~m} / \mathrm{s}$ & {$[36,37]$} \\
Wet day & Precipitation $>5 \mathrm{~mm}$ & {$[30]$} \\
Sunshine & Sky cover $<5 / 8$ & {$[35]$} \\
Foggy day & Relative humidity $>93 \%$ & {$[30]$} \\
Rainy day & Precipitation $>1 \mathrm{~mm}$ & {$[30]$}
\end{tabular}

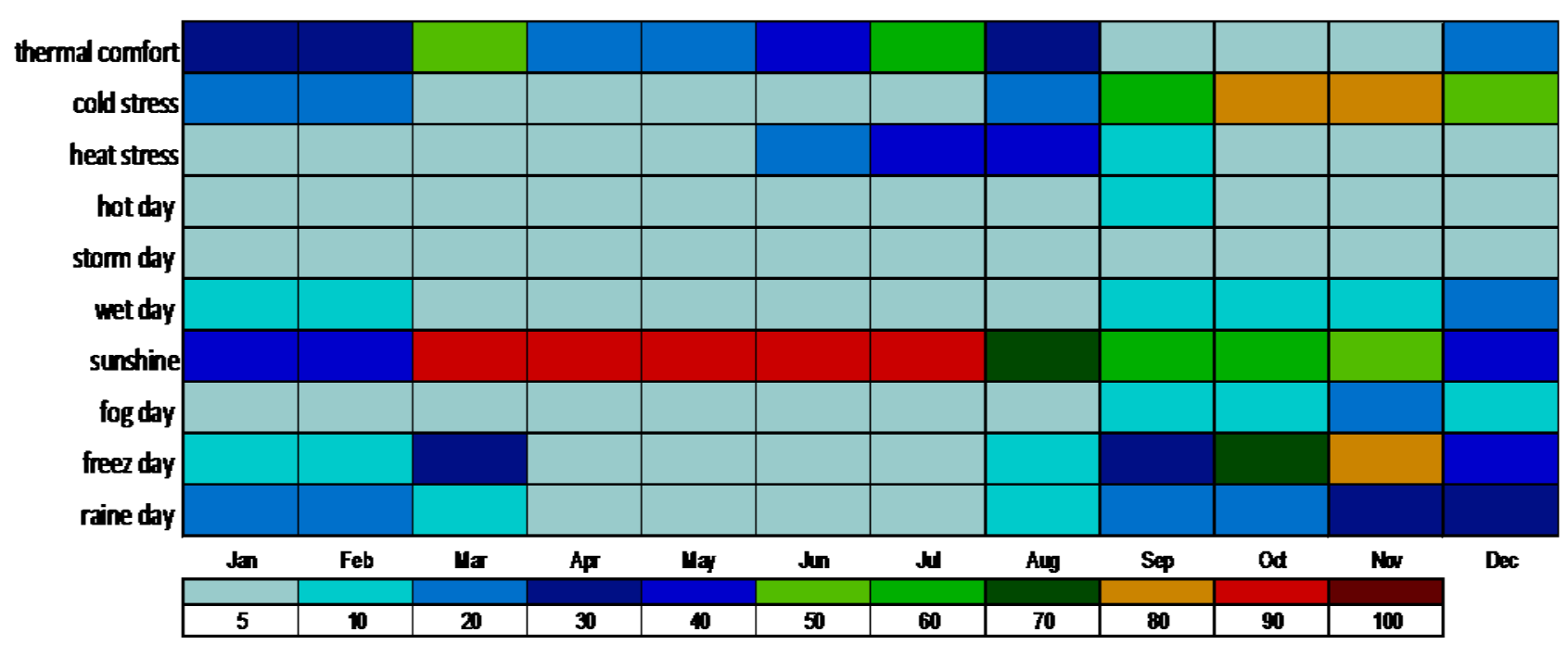

Figure 9. The probability of the occurrence of phenomenon in Mashhad for the period 1978-2007.

manage them properly while facing them.

\section{Conclusion}

As discussed, and with regard to low cold/hot tension ranks, the acceptable range of climatic comfort of PET index can be considered between 13 and 29, and can best be recommended as an appropriate time for tourism. This is based on low heat and cold stress above and below the comfort zone. According to Figure 6, during the period studied (1978-2007), the highest frequency of climatic comfort conditions occurs at 21:30 p.m. Similarly, according to Figure 9, comfortable climate conditions are most likely to occur in March and July. Moreover, based on Figure 5, climate comfort occurs in two periods during the year, between 9:30 and 15:30. The first period is in the spring and the second one in early fall. It should be noted that the comfortable period (21:30 pm) is relatively long in the summer season. Because of heat stress, other times are not good for tourism. The longest climate comfort period occurs at 21:30, and the shortest one occurs at 9:30. The longest period of heat stress occurs at
15:30, and the longest period of cold stress occurs at 21:30. Furthermore, the shortest period of cold stress relates occurs at 15:30. According to Figure 7, the curve of changes in PET index is in a Gaussian shape; therefore, the curves on the high peaks of PET are above $30^{\circ} \mathrm{C}$, and the minimum point is located in the low PET index. The curve is repeatedly consistent within the range of climatic comfort at 21:30 in summer (22nd of June to 22nd of September). However, at the end of summer vacation, only curves of 9:30 are located in comfort climate range, and the curves of 21:30 are outside this range. Nowruz holidays in early spring (21st of March to 2nd of May), only have the curve of 9:30 in the climate comfort zone.

\section{Recommendations}

Based on Figure 5, which shows the distribution of the number of tourists of Mashhad throughout the year, the Peak period of journeys is from April, July to August. Accordingly, the followings are recommended:

1) According to Figure 9, the best hour for journeying in April is 15:30. So it is advisable that tourists leave for 
visits during these hours.

2) Similarly, with respect to Figure 9, the best hour of the climatic comfort in July to August is at 21:30.

3) In the same way, the main bio-climate constraints in Mashhad are high and long cold stress months of December, January, February, and March making the time not suitable for tourism and recreation.

With regards to the items listed above, it can be concluded and summarized that:

1) During the summer holidays (22nd of June to 22nd of September), due to a hot feeling in the afternoons and sometimes early mornings, night time is better for tourism and excursions.

2) During the Nowruz holidays (from 21st of March to 2nd April), which is the peak period of domestic travels and tourism, the cool tensions in the morning and early evening causes some restrictions. But in the afternoons, the climatic conditions are very good for tourism and expeditions.

\section{REFERENCES}

[1] UNWTO, “UNWTO Tourism Highlights: 2011 Edition,” UNWTO, Madrid, 2012.

[2] D. Scott, G. McBoyle and M. Schwartzentruber, "Climate Change and the Distribution of Climatic Resources for Tourism in North America," Climate Research, Vol. 7, 2004, pp. 105-117. www.int-res.com

[3] D. Scott, C. J. Lemieux and L. Malone, “Climate Services to Support Stainable Tourism and Adaptation to Climate Change," Climate Research, Vol. 47, No. 1-2, 2011, pp. 111-122. http://dx.doi.org/10.3354/cr00952

[4] G. Wall and C. Badke, "Tourism and Climate Change: An International Perspective,” Journal of Sustainable Tourism, Vol. 2, No. 4, 1994, pp. 193-203. http://dx.doi.org/10.1080/09669589409510696

[5] K. Blazejczyk, "Weather Limitations for winter and Summer Tourism in Europe,” Developments in Tourism Climatology, 2007.

[6] C. R. De Freitas, "Theory, Concepts and Methods in Climate Tourism Research,” In: A. Matzarakis and C. R. de Freitas, Eds., Proceedings of the First International Workshop on Climate, Tourism and Recreation, International Society of Biometeorology, Commission on Climate Tourism and Recreation, 2001, pp. 3-20. www.mif.uni-freiburg.de/isb/ws/papers/full_report.pdf

[7] E. C. Thom, “The Discomfort Index. Weatherwise 12:5760VDI (1998) Methods for the Human-Biometerological Assessment of Climate and Air Hygiene for Urban and Regional Planning. Part I: Climate. VDI Guideline 3787. Part 2,” Beuth, Berlin, 1959.

[8] P. A. Siple and C. F. Passel, "Measurements of Dry Atmospheric Cooling in Subfreezing Temperatures," American Philosophical Society, Vol. 89, 1945, pp. 177-199.

[9] V. Olgy, “Design with Climate," Princeton University Press, 1973, p. 185.
[10] W. H. Terjung, "World Patterns of the Monthly Comfort Index,” International Journal of Biometeorology, Vol. 12, No. 2, 1968, pp. 119-123,141. http://dx.doi.org/10.1007/BF01553502

[11] Z. Mieczkowski, "The Tourism Climate Index: A Method for Evaluating World Climates for Tourism,” The Canadian Geographer, Vol. 29, 1985, pp. 220-233. http://dx.doi.org/10.1111/j.1541-0064.1985.tb00365.x

[12] A. Matzarakis and H. Mayer, “Another Kind of Environmental Stress: Thermal Stress. WHO Collaborating Centre for Air Quality Management and Air Pollution Control,” NEWSLETTERS, Vol. 18, 1996, pp. 7-10.

[13] D. I. Verein, “VDI 3787, Part I: Environmental Meteorology, Methods for the Human-Biometeorological Evaluation of Climate and Air Quality for the Urban and Regional Planning at Regional Level. Part I: Climate," VDI/DIN-Handbuch Reinhaltung der Luft, Band 1b, Düsseldorf, 1998, 29 p.

[14] P. Hoppe, “The Physiological Equivalent Temperature-A Universal Index for the Biometeorological Assessment of the Thermal Environment," International Journal of Biometeorology, Vol. 43, 1999, p. 7175.

[15] A. Matzarakis, H. Mayer and M. G. Iziomon, "Applications of a Universal Thermal Index: Physiological Equivalent Temperature,” International Journal of Biometeorology, Vol. 43, 1999, pp. 78-84.

[16] A. P. Gagge, A. P. Fobelets and L. G. Berglund, “A Standard Predictive Index of Human Response to the Thermal Environment,” ASHRAE Transactions, Vol. 92, 1986, pp. 709-731.

http://www.osti.gov/energycitations/product.biblio.jsp?os $\underline{\text { ti_id }=6494216}$

[17] J. Spagnolo and R. de Dear, “A Field Study of Thermal Comfort in Outdoor and Semi-Outdoor Environments in Subtropical Sydney Australia,” Building and Environment, Vol. 38, No. 5, 2003, pp. 721-738. http://dx.doi.org/10.1016/S0360-1323(02)00209-3

[18] M. Kasmai, “Climate and Architecture,” Publishing Territory, Isfahan, 1990. Chapter II.

[19] M. R. Kaviani, “The Study and Zonation Map of Human Bioclimatic of Iran,” Geographical Research Quarterly, Vol. 48, 1993, pp. 47-65.

[20] M. R. Kaviani, H. Ghayoor and N. Payandeh, "Assessment of Effective Temperature in Iran,” Geography Research Journal, Vol. 80, 2007, pp. 11-29.

[21] M. Farajzadeh and A. Ahmad Abadi, ,. Assessment and Mapping of Iranian Tourism Climate Using Tourism Climate Index (TCI),” Journal of Geographical Research, Vol. 71, No. , 2010, pp. 31-42.

[22] H. Zolfaghari, "Determination of Suitable Calendar for Tourism in Tabriz with Using the Thermo-Physiological Indices (PET and PMV)," Geographical Research Quarterly, Vol. 39, No. 62, 2008, pp. 129-141.

[23] R. Esmaili, S. Haghighat, Akram, Malbosi and Sharare, "Assessment of Chabahar Port Climate Relaxing Conditions for Tourism Development," 4th International Congress of the Islamic World Geographers (ICIWG), Zahedan, 14-16 April 2010. 
[24] R. Esmaeili, A. Gandomkar and M. Habibi Nokhndan, "Several Major Cities in the Comfort of Climate Indices Using Physiologically Equivalent Temperature," Natural Geographical Journal, Vol. 75, 2011, p. 1390.

[25] A. Masoodian and M. R. Kaviani, "Climatology,” First Printing, Esfahan University, Esfahan, 2009.

[26] E. A. Grigorieva and A. Matzarakis, "Physiologically Equivalent Temperature in Extreme Climate Regions in the Russian Far East,” In: A. Matzarakis, H. Mayer and F.-M. Chmielewski, Eds., Proceedings of the 7th Conference on Biometeorology, Ber. Meteorol. Inst. Univ., Freiburg, Vol. 20, 2010, pp. 386-391.

[27] P. O. Fanger, “Thermal Comfort,” McGraw-Hill, New York, 1972.

[28] G. Jendritzky, G. Menz, W. Schmidt-Kessen and H. Schirmer, "Methodology for Spatial Evaluation of the Thermal Component in the Bioclimatic of People," Academy of Spatial Research and Planning, Hanover, 1990.

[29] M. C. Thomson, R. Garcia-Herrera and M. Beniston, "Seasonal Forecasts, Climatic Change and Human Health: Health and Climate," Springer Science + Business Media B.V, 2008, 232 p.

[30] A. Matzarakis, "Climate Thermal Comfort and Tourism," Proceedings of the 2nd International Workshop on Climate Change and Tourism Assessment and Coping Strategies, Bas Amelung, Krzysztof Blazejczyk, Andreas Matzarakis, 2007.

[31] T.-P. Lin and A. Matzarakis, "Tourism Climate Information Based on Human Thermal Perception in Taiwan and
Eastern China,” Journal of Tourism Management, Vol. 32, No. 3, 2011, pp. 492-500.

http://dx.doi.org/10.1016/j.tourman.2010.03.017

[32] A. Matzarakis, "Assessing Climate for Tourism Purposes Existing Methods and Tools for the Thermal Complex," In: A. Matzarakis and C. R. de Freitas, Eds., Proceedings of the 1st International Workshop on Climate, Tourism and Recreation, International Society of Biometeorology, Commission on Climate, Tourism and Recreation, Greece, 2001, pp. 101-113. www.mif.uni-freiburg.de/isb/ws/papers/full_report.pdf

[33] A. Mayer and A. Matzarakis, "Humman Biometeorological Assessment of the Urban Climate Method, Results, Deficiencies," Meteorological Institute, University of Freiburg Press, Germany, 2003.

[34] B. Alijani, “Iran’s Climate,” 2003.

[35] A. Matzarakis, F. Rutz and H. Mayer, "Modelling Radiation Fluxes in Simple and Complex Environments-Application of the RayMan Model," International Journal of Biometeorology, Vol. 51, No. 4, 2007, pp. 323-334. http://dx.doi.org/10.1007/s00484-006-0061-8

[36] M. B. Gomez Martın, “An Evaluation of the Tourist Potential of the Climate in Catalonia (Spain): A Regional Study,” Geografska Annaler, Vol. 86, No. 3, 2004, pp. 249-264. http://dx.doi.org/10.1111/j.0435-3676.2004.00229.x

[37] J. P. Besancenot, “Climat et Tourisme,” Masson édit. Collection Géographie, Paris, 1990. 